\title{
Impacts of Climate Change on Rainfall Indices Estimation in Some
}

\section{of Subbasins West of Iran}

\author{
Hadi Nazaripouya ${ }^{*}$, Faculty member of Agriculture and Natural Resources Research and education Center \\ of Hamedan Province \\ Email:hnpoya@yahoo.com
}

\begin{abstract}
:
Future projections from climate models and recent studies shows impact of climate change on rainfall indices estimation. This study assesses the simulations of rainfall indices based on the Coupled Model Intercomparison Project CMIP5 and CMIP3 in the some of subbasin Hamedan Province West of Iran. The analysis of the rainfall indices are: simple rainfall intensity, very heavy rainfall days, maximum one-day rainfall and rainfall frequency has been carried out in this study to evaluating the impact of climate change on rainfall indices events. Relative change in three rainfall indices is investigated by GCMs under various greenhouse gas emission scenarious $\mathrm{A} 1 \mathrm{~B}$ and $\mathrm{B} 1$ and RCP8.5, RCP8.5 scenarios for the future periods 2020-2045 and 2045-2065. The final results show that each of rainfall indices differs in stations under the three GCMs model (GIAOM, MIHR, MPEH5) and emission scenarios A1B and B1, and RCP2.5, RCP8.5 scenarios. Relative change of daily intensity index varies from $-9.93 \%-25 \%$, very heavy rainfall days $20.71 \%-25.9 \%$ and yearly rainfall depth $-15.71 \%-13 \%$ can be observed at study area in 50y for future periods (2046-2065). Rainfall indices of sum wet days, nday $>1 \mathrm{~mm}$ and maximum one-day rainfall are projected to decrease under the senariuos B1,A1B and sum wet days, simple daily intensity and heavy Rainfall days $>10$ projected to decrease under the RCP2.6.
\end{abstract}

key words : climate change; rainfall indices; uncertainty; LARS-WG; Hamedan province 


\section{Introduction}

Changes in the climate and especially in rainfall characteristics are expected to have a strong impact on the living onditions of the population in study area. Decreasing rainfall amounts or increasing dry spells would negatively affect crop yields in the region. Increasing rain amounts, especially during the dry season, however, would have a positive effect as the cultivation period of staple crops could be extended. CMIP5 is the Coupled Model Intercomparison Project Phase 5, which provides a framework for coordinated climate change experiments for the next several years and includes simulations for assessment in the AR5 as well as for other assessment reports that extend beyond the AR5 (Taylor etal., 2012). Relative to earlier phases, CMIP5 focuses on a set of experiments that include higher spatial resolution models, improved model physics, and a richer set of output fields (Gulizia and Camilloni, 2015; Taylor et al., 2012). Additionally, the CMIP5 climate change projections are driven by new climate scenarios that use a time series of emissions and concentrations from the representative concentration pathways (RCPs) described in Moss et al (2010). Accordingly, GCMs provided by the CMIP5 have been widely used in the assessment of climate change (Gulizia and Camilloni, 2015; Pierce et al., 2013; Smith et al., 2013).

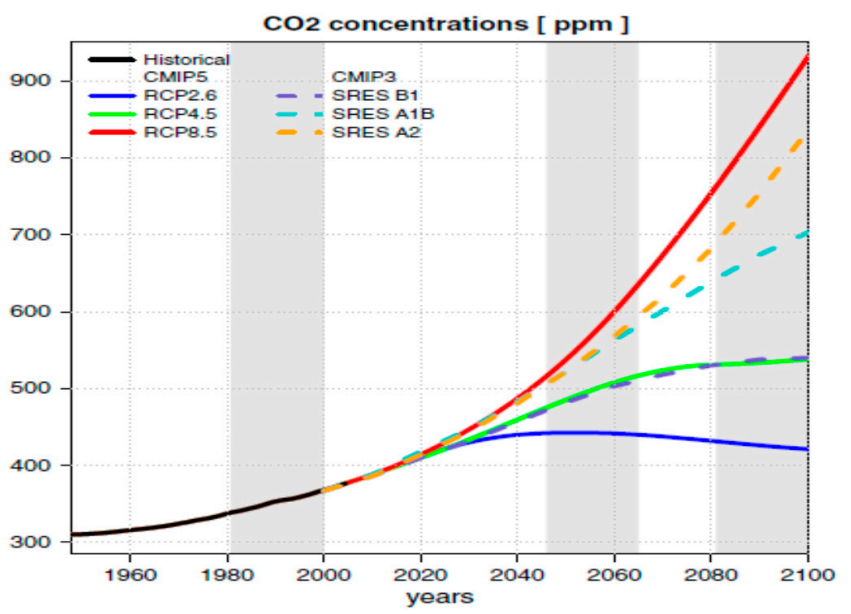

Fig 1. Carbon dioxide (CO2) concentrations in ppm as used in the CMIP3 and CMIP5 historical and scenario simulations and available for download at the PCMDI website. The vertical shading indicates the reference period (1981-2000) and the two 20 year periods (2046-2065 and 20812100) considered in the analysis of future climate change.( J. Sillmann et all 2016). 
Fig 1 illustrates the evolution of carbon dioxide (CO2) concentrations as observed in the 20th century and prescribed in the 21st century simulations in the SRES and RCP scenarios considered in this study. Furthermore, the models may respond differently to a specific radiative forcing due to different modelspecific climate sensitivities. However, based on the underlying radiative forcing (or $\mathrm{CO} 2$ concentrations), one can compare projected changes in the precipitation indices and provide an estimate of uncertainty related to the different emission scenarios.However understanding the changes in the extremes weather events is more important than the changes in mean pattern for better disaster management and mitigation. Therefore, there is a need to know the magnitudes of extreme rainfall events over different parts of the world spatially in in the some of subbasin Hamedan Province West of Iran. Future climate change is generally believed to lead to an increase in climate variability and in the frequency and intensity of extreme events in most of studies. Various studies investigated that the frequency and magnitude of extreme rainfall, for both global and regional scales under the enhanced greenhouse gases (GHGs) conditions. Many General Circulation Models (GCMs) results consistently predict inreases in the frequency and magnitudes of extreme climate event and variability of rainfall (IPCC, 2007). Andreas Haensler et al. (2013) assessing the CMIP3 and CMIP5 databases, along with some recently downscaled regional CORDEX Africa projections conclued that independent of the underlying emission scenario, nnual total precipitation amounts over the central African region are not likely to change severely in the future and some robust changes in precipitation characteristics, like the intensification of heavy rainfall events as well as an increase in the number of dry spells during the rainy season are projected for the future .Seree Supharatid et al. (2015) studied assessment of CMIP3-CMIP5 climate models precipitation projection and implication of flood vulnerability of Bangkok and conclued that Use of the Multi Model mean shows continuously increased rainfall from the near future to the far future while the Multi Model Median shows increased rainfall only for the far future.Saeed et al. (2013) investigate the reasons for the opposite climate change signals in precipitation between the regional climate model REMO and its driving earth system model MPI-ESM over the greater Congo region. Three REMO simulations following three 
RCP scenarios (RCP 2.6, RCP 4.5 and RCP 8.5) are conducted, and it is found that the opposite signals, with REMO showing a decrease and MPI-ESM an increase in the future precipitation, diverge strongly from a less extreme to a more extreme scenario.Zhou et al. (2014) presents projected changes in temperature and precipitation extremes in China by the end of the twenty-first century based on the Coupled Model Intercomparison Project phase 5 (CMIP5) simulations. The temporal changes and their spatial patterns in the Expert Team on Climate Change Detection and Indices (ETCCDI) indices under the RCP4.5 and RCP8.5 emission scenarios are analyzed. Compared to the reference period 1986-2005, substantial changes are projected in temperature and precipitation extremes under both emission scenarios. These changes include a decrease in cold extremes, an increase in warm extremes, and an intensification of precipitation extremes.Pourtouiserkani et al. (2014) studied, climate change impact on the extreme rainfall using two AOGCM models outputs (HadCM3 and CGCM3). Outputs of the Atmospheric model rainfall data were downscaled (from monthly to daily) for the future period of 2020s (2011-2040) using statistical downscaling techniques,Change factor, LARS-WG stochastic weather generator, and SDSM, at the Chenar-Rahdar basin, Fars, Iran. Based on the rainfall time series generated by downscaling methods, maximum 24-hour rainfalls for the two AOGCM models were extracted and a frequency analysis was performed to get future daily rainfalls with different return periods. Comparing the three downscaling techniques utilized in this study. it is concluded that using change factor and also LARS-WG downscaling methods would be conservative enough methods in the climate change impact assessment for the next 30 years.Yue-Ping Xu et al. (2012) investigate the possible impact of climate change on extreme rainfall in the Qiantang River Basin for three future periods 2020s (2011-2030), 2045-2065 (2046-2065) and 2090s (2080-2099) and to investigate the uncertainty in the evaluation by employing three GCMs model and three emission scenarios.Results showed that the 24-h design rainfall depth increases in most of stations under the three GCMs and emission scenarios and there are large uncertainties involved in the estimations of 24-h design rainfall depths at seven stations because of GCMs, emission scenarios and also other uncertainty sources.Babaian et al. (2009) studied climate change impact in the Iran and used Echo-G output data based on the A1 emission scenario for 43 sinoptic stations . Results showed that decrease 
$9 \%$ total rainfall but heavy and very heavy rainfall in turn increase $13 \%$ and $39 \%$ for the period 2010 2039 and conclude that whit respect to decrease rainfall and increase in heavy rainfall in Iran country cause to rainstorm and heavy rainfall in in future decads.One way of the converting globally scaled CMIP3 and CMIP5 climate models to a watershed scale is through the use of downscaling techniques. A wide variety of methods have been employed to downscale AOGCM data. Two major groups of statistical downscaling tools are: 1 regression based (transfer function) methods and 2 stochastic weather generators (Dibike and Coulibaly, 2005; Ying et al., 2011). Stochastic weather generators technique can be classified in three main categories: parametric, semi-parametric, and non- parametric. An advantage of the weather generators is that they can be used to generate synthetic time series of any length, and thus the frequency and probability of extreme events can be examined. Leanna et al. (2009) found that the uncertainty originated from GCM structure is the largest source of uncertainty when comparing different uncertainty sources for climate change impacts analysis on the flood frequency in England.

Therefore in this study in order to estimate potential impacts of climate change and to identify rainfall characteristics assesing the impact of climate change on rainfall indices in the Kooshkabad watershed for tow future periods 2020-2045 and 2045-2065 under the three GCMs and tow emission scenarios are categorized as medium A1B and lower forcing B1 and RCP2.5, RCP8.5 scenarios. List of CMIP3 and CMIP5 global climate models used in this study presented in Table 1. The contents of this paper are organized as follows. The first introduces the study area and data used. After methodologies used in this paper that including stochastic weather generator (LARS-WG) and Change factor with Change in mean and variance method for generate daily rainfall CIMP5model data downscale the future GCM climate. 
6

Table 1. List of CMIP3 and CMIP5 global climate models used in this study

\begin{tabular}{|c|c|c|c|c|c|c|}
\hline Research centre & Country & $\begin{array}{l}\text { Global } \\
\text { climate } \\
\text { model }\end{array}$ & $\begin{array}{c}\text { Model } \\
\text { acronym }\end{array}$ & $\begin{array}{l}\text { Grid } \\
\text { resolution }\end{array}$ & $\begin{array}{l}\text { Emissions } \\
\text { scenarios }\end{array}$ & Source \\
\hline $\begin{array}{c}\text { National Institute for } \\
\text { Environmental }\end{array}$ & Japan & $\begin{array}{c}\text { MRI- } \\
\text { CGCM2.3.2 }\end{array}$ & MIHR & $2.8 \times 2.8^{\circ}$ & SRA1B, SRB1B & $\begin{array}{l}\text { K-1 Model Developers } \\
\qquad \begin{array}{c}\text { (2004) } \\
\text { Studies }\end{array}\end{array}$ \\
\hline $\begin{array}{c}\text { Max-Planck Institute } \\
\text { for Meteorology }\end{array}$ & Germany & $\begin{array}{l}\text { ECHAM5- } \\
\text { OМ МРЕН5 }\end{array}$ & MPEH5 & $1.9 \times 1.9^{\circ}$ & $\begin{array}{l}\text { SRA1B, SRA2, } \\
\text { SRB1B }\end{array}$ & Roeckner et al. (1996) \\
\hline $\begin{array}{c}\text { Goddard Institute for } \\
\text { Space Studies }\end{array}$ & USA & GISS-AOM & GIAOM & $3 \times 4^{\circ}$ & SRA1B, SRB1B & $\begin{array}{c}\text { Russell et al. } \\
\text { (1995) }\end{array}$ \\
\hline $\begin{array}{c}\text { Max Planck Institute } \\
\text { for Meteorology, } \\
\text { GermanyMPI- }\end{array}$ & Germany & ESM-LR & MPI & $\begin{array}{l}1 / 875 \times \\
1 / 85^{\circ}\end{array}$ & $\begin{array}{c}\text { RCP2.5, } 8.5 \\
\text { scenario }\end{array}$ & Raddats et all . (2007) \\
\hline
\end{tabular}

\section{Materials and methods}

\subsection{Study area}

The study area location is the $2400 \mathrm{~km} 2$ kooshkabad watershed, located in Iran-Hamedan province $34^{\circ} 48^{\prime}$ to $34^{\circ} 85^{\prime} \mathrm{N}$ and $48^{\circ} 26^{\prime}$ to $48^{\circ} 67^{\prime} \mathrm{E}$ ) Fig 2 , gives an overview of the study area location. The topography is rather complex, with elevation ranging from around $1750 \mathrm{~m}$ to around $3570 \mathrm{~m}$. Annual rainfall shows strong variations within the catchment, ranging from around $250 \mathrm{~mm}$ to $750 \mathrm{~mm}$, based on the period 1983- 2010. Maximum monthly rainfall at the study area occurs during mars with an average of $56.65 \mathrm{~mm}$, whereas minimum monthly rainfall is observed in septamber, $0.38 \mathrm{~mm}$. Monthly minimum temperature occurs during Februery, $-1.5^{\circ} \mathrm{C}$, whereas monthly maximum temperature is observed in July with +22.5 C. The climate of study area semiarid with dry summer, humid and cold in winter and humid spring respectively. 


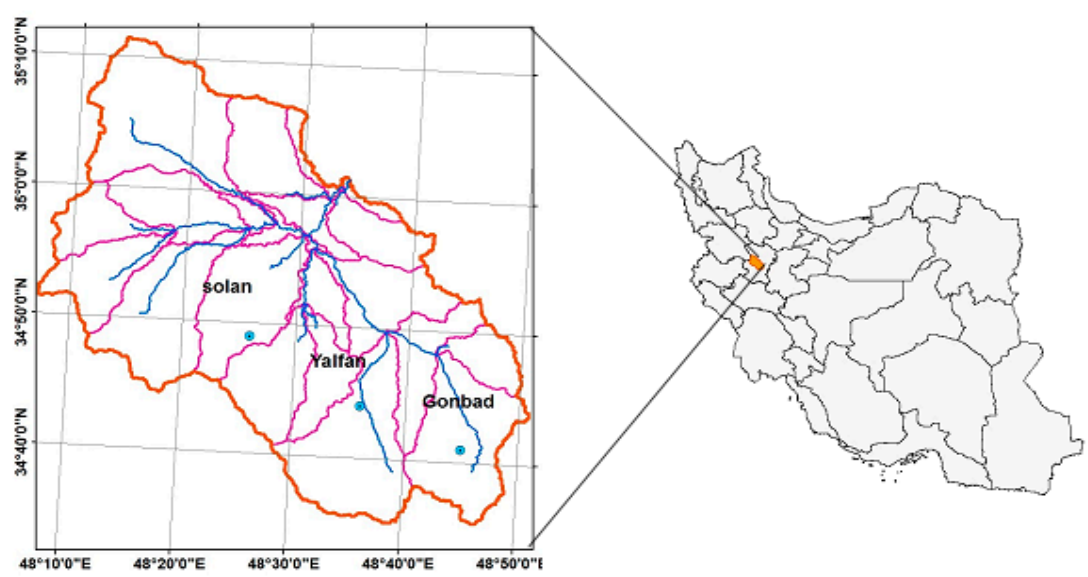

Fig 2: study area location

\section{2 methdology}

\subsection{1 climate scenarios approach}

In this study we analyze climate simulations of the 20 th and 21 stcentury performed by models CMIP 3 and CMIP5 on rainfall indices estimation in Kooshkabad watershed. The observation data were recieved from the Hamedan Province Meteorological Organization (HPMO). However our analyses are limited to 3 stations because of this three station have long and favor data. Compared with the emission scenarios in CMIP3 and CMIP5 the representative concentration pathways (RCP) related to the radiative forcing are identified as new climate scenarios in CMIP5, and they include RCP2.6, RCP4.5, RCP6.0, and RCP8.5. So in this study, we mainly focus on the changes in extreme rainfall events in study area at the end of the 21st century based on the CMIP3, A1b , B1 emisions scenarios and CMIP5 models in the RCP2.5 (medium radiative forcing scenario) and RCP8.5 (high radiative forcing scenario) scenarios. The daily rainfall outputs from one CMIP5 model for the period of 2020-2064 in the RCP2.5 and RCP8.5 scenarios and outputs from three CMIP3 model are used here. In the low emissions (RCP2.6) scenario, atmospheric CO2 concentration peaks at just over $440 \mathrm{ppm}$ in 2050 and then declines to 420 ppm by the year 2100 . Methane concentration peaks at just over $1770 \mathrm{ppb}$ in 2010 and then declines rapidly, reaching around 1250 ppb by 2100 . The RCP2.6 scenario has total CO2 emissions (total5fossil fuel industry land use 
change) similar to present-day levels until 2020 and then a sharp decline to zero carbon emissions by 2075 . The high emissions (RCP8.5) scenario is characterized by a progressive increase in atmospheric $\mathrm{CO} 2$ concentration over the twenty-first century, peaking at $935 \mathrm{ppm}$ in 2100 . Methane also shows a very significant rise in the atmosphere under this scenario, peaking at $3750 \mathrm{ppb}$ in 2100 . Total CO2 emissions increase from present-day values to a maximum of around $28 \mathrm{PgC} \mathrm{yr} 21$ in 2100 (at which point the emissions curve flattens). The CO2-equivalent concentration for greenhouse gases in the year 2100 (i.e., the concentration of $\mathrm{CO} 2$ that would be present in the atmosphere is $\mathrm{CO} 2$ were the only greenhouse gas accounting for all the greenhouse forcing) is $475 \mathrm{ppm}$ for the RCP2.6 scenario, and over $1300 \mathrm{ppm}$ for the RCP8.5 scenario. For each of the RCPs, tow ensemble members were run.

In this study, some rainfall indices have been used for comparing the performances of the CMIP3 and CMIP5 for generating rainfall indices amounts. Rainfall indices asesing in this study are; sum wet days , simple rainfall intensity, very heavy rainfall days (count of days where $R R \geq 20 \mathrm{~mm}$ ), maximum one-day rainfall and frequency, were considered in this study.

Data Downscaled with statistical downscale method, LARS-WG, change factor $(\mathrm{CH})$ and bias corrected statistical.We analyze projected changes in daily precipitation extremes and several precipitation indices. In this reaserch the output of the three GCMs model (MPE5, GIOAM, MIHR ) was downscaled using the LARS-WG model to generate daily rainfall for CIMP3 .Also the Change factor method with Change in mean and variance used for generate daily rainfall CIMP5 model data. The emission scenarios are categorized as medium, A1B (700 ppm by 2100) and lower forcing, B1 (,550 ppm by 2100). From all simulations the time slices from 1983 to 2010, considered as reference period, and periods (2020-2030), (2046-2065), as a future scenario, were extracted.

\subsubsection{Downscaling approach}

\subsubsection{LARS-WG Technique}

LARS-WG technique was developed in UK by Dr. Mikhail Semenov as a tool for agricultural impact ssessments (Racsko et al.,1991; Semenov and Porter, 1994;Semenov and Barrow, 1997). LARS-WG is used for the simulation of weather data at a single meteorological station because of its capability of 
simulating extreme weather events (Semenov et al., 1998; Semenov, 2008). The model uses time series of rainfall, maximum and minimum temperatures, and solar radiation as inputs. LARS-WG analyzes the observed rainfall series in order to determine the statistics of wet-day occurrence and mean daily rainfall. From this, semi empirical distributions are developed to simulate wet and dry-spell lengths with daily rainfall amounts conditional on the spell length (Semenov and Barrow, 2002; Khan et al., 2006; Hashmi et al., 2011). LARS-WG is used to generate synthetic historical climate data as well as data for each AOGCM and emissions scenario. So stochastic weather generator is used to generate daily rainfall patterns that are statistically similar to the observed patterns .

After generate future climate change data using LARS-WG for stations, F-Test statistical was used to compare the distributions of observed and simulated rainfall indices during the baseline period (19832010). The significance level was set to $=0.05$. Results obtained from F-Test statistical , all of rainfall indices are significant.

\subsubsection{Change factor}

The change factor approach is a method that makes the output of GCMs useful for catchment scale analysis and hydrological modeling (which means that the GCM outputs are used indirectly). The method is based on the use of a change factor, the ratio between a mean value in the future and historical run. This factor is then applied to the observed time series to transform this series set into time series that is representative of the future climate.The future daily rainfall $(P F u t, d)$ is obtained by multiplying the observed daily series $(P O b s, d)$ by the ratio of the mean monthly rainfall value for the GCM scenario series $(P S c e, m)$ to the control series $(P C o n, m)$.

P Fut $d=$ PObs $d \times$ PSce $m / p$ Con $m$

In this study the method of Change in mean and variance suggested by Leander and Buishand (2007) used for downscaling outputs CMIP5 data models. This method is based on a non-linear correction approach and corrects the mean and variance of the observed time series using the CF of the mean and variance. 


\section{Results}

\subsection{Effects of Climate Change on Monthly Rainfall}

In this section , impact of climate change on monthly rainfall was briefly analyzed for period 2045-2065 (2046-2065) on basis of 3 GCMs model and emission scenarios ,A1B and B1. For 2045-2065 period synthetic daily rainfall data are generated by LARS-WG. Monthly rainfalls from different GCMs and emission scenarios are then extracted from out pout LARS-WG and calculated for different stations . Fig 2(a)-(c) box polt graphs shows the relative changes of monthly rainfall compared with GCM projections during the baseline period (1983-2010) under the three different scenarios in region .

(a)

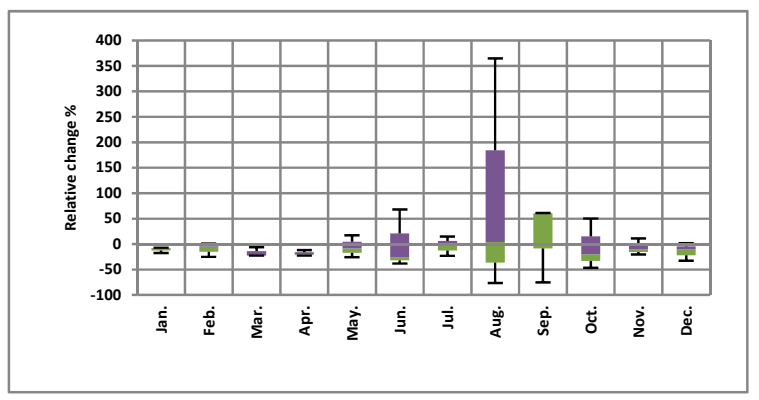

(b)

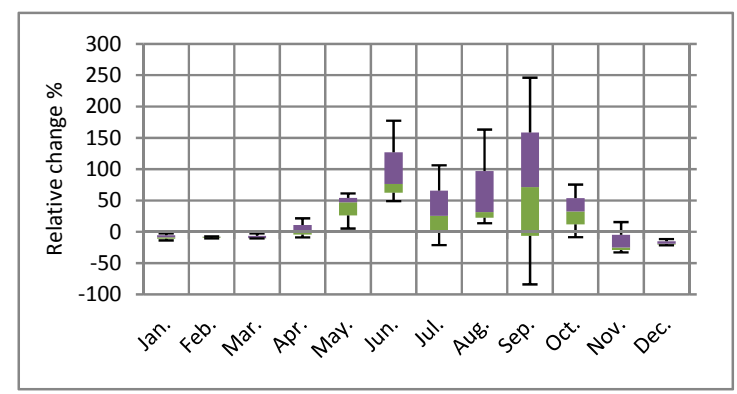

(c)

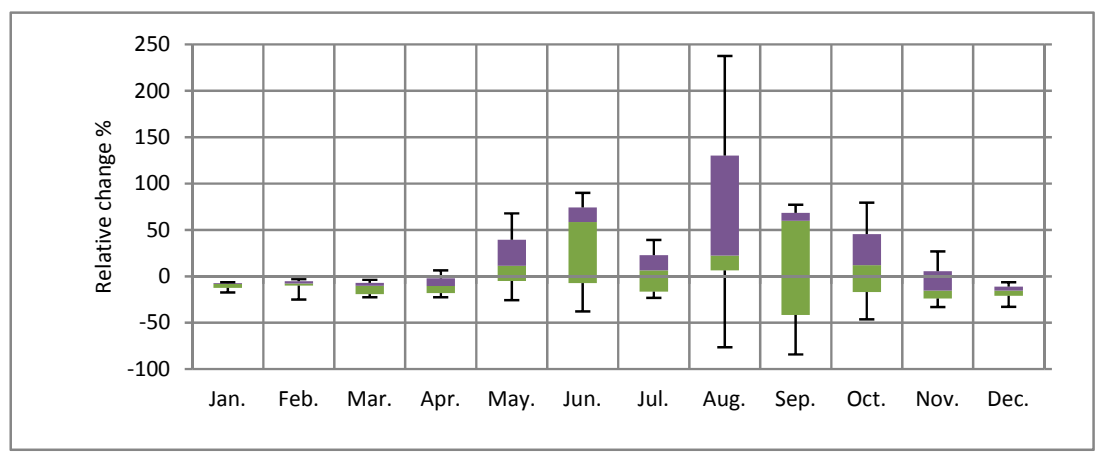

Fig 2 (a)-(c) box polt graphs of Relative changes of monthly precipitation for the future 2045-2065 under the three three GCMs model (MPE5, GIOAM,MIHR) scenarioA1B (a) scenarioB1(b) and combined scenario A1B \& B1 (c). 
Fig2(a) showed that the relative change monthly rainfall varies under the three GCMs model (MPE5, GIOAM,MIHR ) scenarioA1B for the period 2045-2065. Range of relative change in January varies from $-7 \%$ to $-17.4 \%$ and relative change from January to june and November, December ranges from $17.2 \%$ to $-32 \%$.It can be observs that monthly rainfall decreases in the most of months . under the three GCMs scenarioB1, Fig 3(b) showed that Range of relative change in January varies from $-2.5 \%$ to $-13.9 \%$ and five months decrease in rainfall and other months increase in monthly rainfall with large uncertainity. It is found that in the three GCMs model, relative change rainfall varies under emission scenarios ,A1B and B1. In the emission scenarios ,A1B decreasing in monthly rainfall more than in scenarios B1. Using combination models, Fig 2(c) and emission scenarios it can be found that rainfall increasing slightly with large uncertainty in the warm period and decreasing in the cold period respectively for future period (2046-2065).

The results showed that decreasing in rainfall in Jan , Feb , Mars , April , November and December with lowest uncertainty and increase in rainfall in May, June and August with the highest uncertainty.

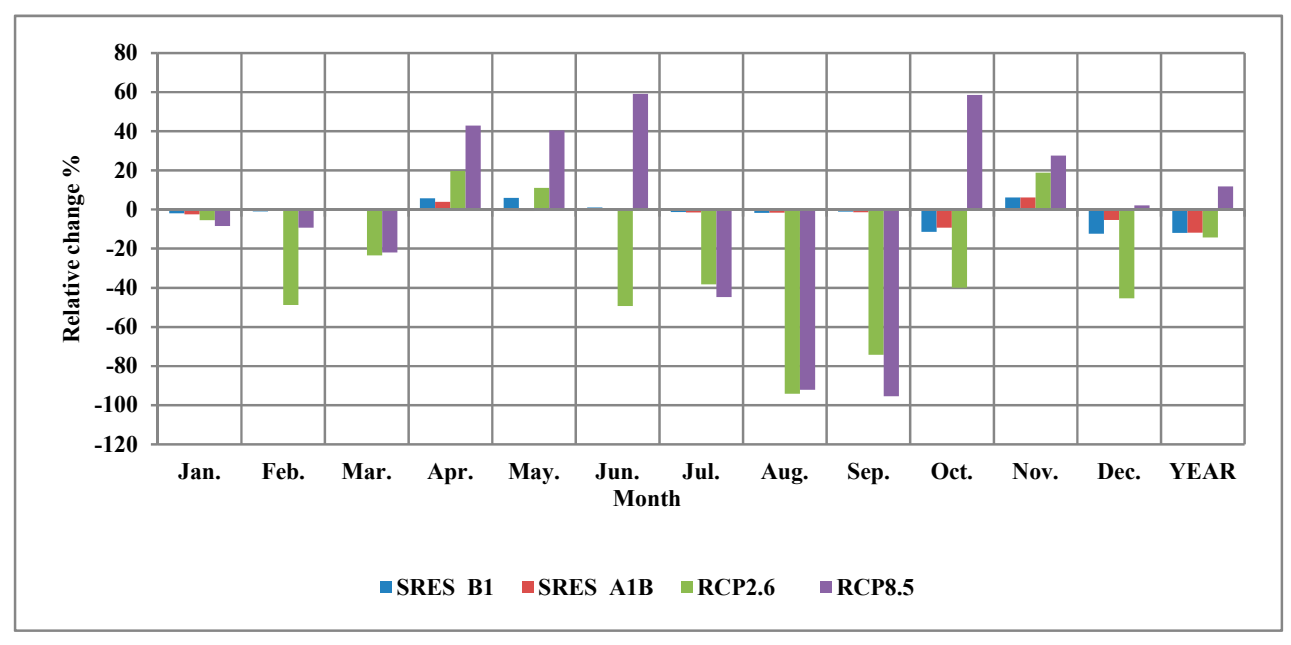

Fig 3. Comparison CMIP3 and CMIP5 models of average monthly precipitation for 2020-2045 period based on reference period (1983-2010)

The relative change monthly rainfall varies under the three GCMs model (MPE5, GIOAM,MIHR ) scenario A1B, B1 and RCP2.6 RCP8.5 scenarios for the future period 2020-2045, Fig3. Range of 
relative change in January varies from $-8.5 \%$ to $-1.9 \%$ and relative change in all month ranges from 95.4\% on Sep to 59\%. on Jun under under the three GCMs model (MPE5, GIOAM,MIHR ) scenario A1B, B1 and RCP2.6 RCP8.5 scenarios for the future period 2020-2045. The hiest relative change in rainfall month predict to exsist on warm season under the RCP2.6 RCP8.5 scenarios. The relative change of average monthly rainfall predict to decrease in the winter under the CIMP3 and CIMP5 models for 2020-2045 period. Fig 3.Also it can be observ that monthly rainfall decreases in the most of months , relative change of yearly rainfall varies from $10.92 \%$ under RCP2.6 to $-16.04 \%$ SRES A1B Fig 4.

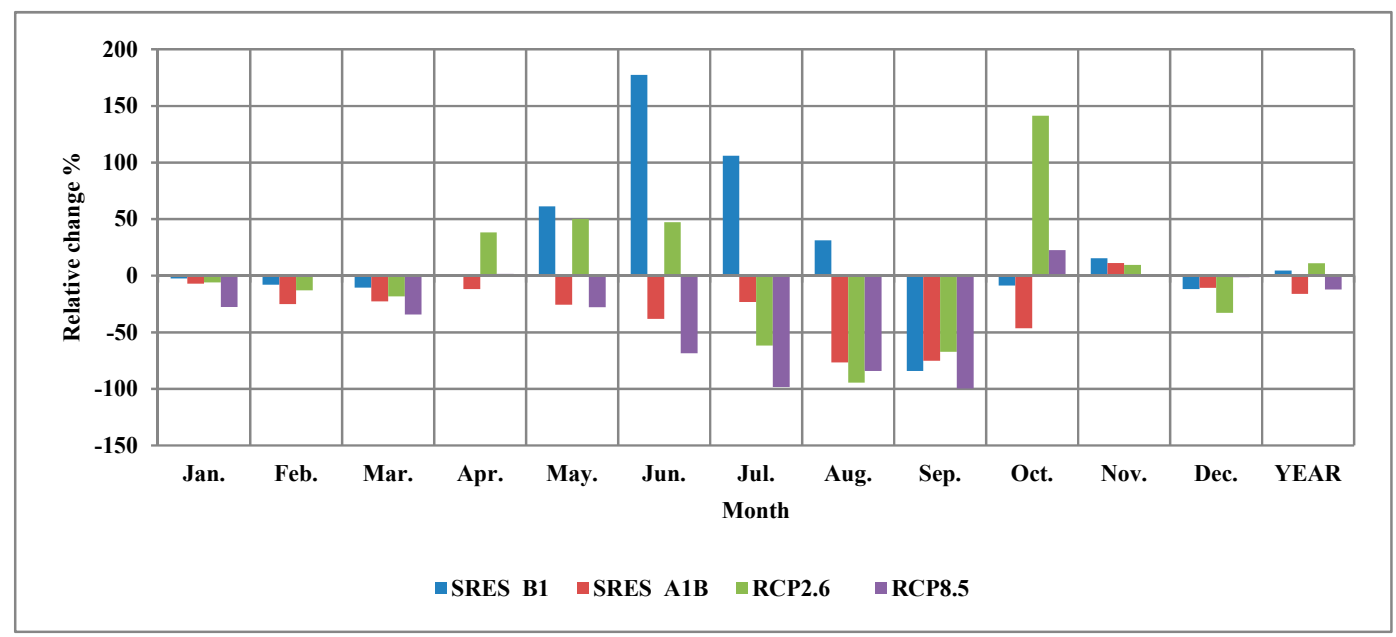

Fig 4. Comparison CMIP3 and CMIP5 models of average monthly precipitation for 2046-2065 period based on reference period (1983-2010)

\subsection{Rainfall Indices Analysis by Fitting a Distribution}

After evaluating that two data series following the same continuous distribution, simulated rainfall indices estimated and observed data sets were computed and compared. For evaluating frequency and return period and compare tow data series it is nessesary to select the best probability distribution function for evaluating frequency analysis rainfall indices. Table2 extracted and computed the best distribution function for all of simulated rainfall indices and stations. On the basis of RMSE and EF methods the best probability distribution function was selected. Results showed that the most of the data, follow the log Pearson Type III. Computed of observed and simulated for different return periods at three stations by 
log Pearson Type III probability distribution function, Table3. It is observed that the errors are small for the most of return periods and indices.

Table 2 RMSE and EF errors for rainfall indices and probability distribution function in the stations

\begin{tabular}{|c|c|c|c|c|c|c|c|}
\hline \multirow{4}{*}{ Parametrs } & \multirow{2}{*}{ Distributions } & \multicolumn{2}{|c|}{ solan } & \multicolumn{2}{|c|}{ yalfan } & \multicolumn{2}{c|}{ gonbad } \\
\cline { 3 - 8 } & & RMSE & EF & RMSE & EF & RMSE & EF \\
\hline \multirow{4}{*}{$\begin{array}{c}\text { Simple } \\
\text { Daily }\end{array}$} & Normal & 0.33 & 0.95 & 0.17 & 0.97 & 0.31 & 0.93 \\
\cline { 2 - 8 } Intensity & Lognorm2par & 0.38 & 0.94 & 0.19 & 0.96 & 0.27 & 0.95 \\
\cline { 2 - 9 } & Lognorm3par & 0.38 & 0.94 & 0.19 & 0.96 & 0.25 & 0.95 \\
\cline { 2 - 9 } & Pearson typ3 & 0.32 & 0.96 & 0.17 & 0.97 & 0.25 & 0.95 \\
\cline { 2 - 8 }$y$ & Logpearson typ3 & $\underline{0.3}$ & $\underline{0.96}$ & $\underline{0.15}$ & $\underline{0.97}$ & 0.25 & 0.95 \\
\cline { 2 - 8 } & Gambel1 & 0.49 & 0.9 & 0.26 & 0.92 & $\underline{0.22}$ & $\underline{0.96}$ \\
\hline
\end{tabular}

Table. 3 rainfall indices estimated on different return period in the Yalfan station

\begin{tabular}{|c|c|c|c|c|c|c|}
\hline parametres & R Period & 100 & 50 & 25 & 10 & 5 \\
\hline \multirow{3}{*}{$\begin{array}{l}\text { Simple Daily } \\
\text { Intensity Index }\end{array}$} & Observed & 9.4 & 9.2 & 8.9 & 8.5 & 8 \\
\hline & Simulated & 9.8 & 9.5 & 9.1 & 8.6 & 8.1 \\
\hline & Error & 4.4 & 3.4 & 2.5 & 1.3 & 0.2 \\
\hline \multirow{3}{*}{$\begin{array}{c}\text { Maximum one-Day } \\
\text { Rainfall }\end{array}$} & Observed & 69.5 & 62.9 & 56.4 & 47.6 & 40.7 \\
\hline & Simulated & 63.4 & 58.5 & 53.5 & 46.4 & 40.4 \\
\hline & Error & 8.9 & 7 & 5.1 & 2.6 & 0.7 \\
\hline \multirow{3}{*}{$\begin{array}{c}\text { Heavy Rainfall } \\
\text { Days }>=20\end{array}$} & Observed & 8.4 & 7.3 & 6.3 & 4.9 & 3.8 \\
\hline & Simulated & 7.7 & 6.8 & 5.8 & 4.5 & 3.5 \\
\hline & Error & 7.9 & 7.9 & 7.8 & 8.1 & 8.7 \\
\hline
\end{tabular}


In this study after analizing frequency distribution, Log Pearson Type III distribution selected the best frequency distribution fitted to the data for CMIP3and CMIP5 models.

\subsection{Assessment of climate change impacts on Rainfall Indices}

Daily climate model data sets over stuty area were analized by CMIP3 and CMIP5 data models. For CMIP3, we chose the GIOAM , MIHR , CMIP3 models which provide the Rainfall Indices data for provide Rainfall Indices data under historical period (1983-2010).

For evaluating relative change in three GCMs model and scenarious, 50y return period computed and compare with base period (1983-2010).The relative changes of calculated 50y return period for rainfall indices estimated and base period on the log Pearson Type III probability distribution function shows in the Fig 5, 6 and 7(a)-(d) box polt graphs.Here is focused on the analysis of the possible future changes in 50y design rainfall depths based on different GCMs and scenarios.

Fig 5(a) and (b) shows relative changes in 50y simple daily intensity, decreasing in Gonbad and increasing in Solan and Yalfan stations for the future 2020-2045 for scenario A1B and B1. But under the scenario A1B Fig 5 (c) increasing only Solan and decreasing in Gonbad and solan, also under scenario B1 (d) increase in Solan and Yalfan, decrease in Gonbad for future 2045-2065 with respect to the base period.Fig 6 (a) - (d) box polt graphs of Relative changes in50y maximum one-day rainfall for the future 2045-2065 for scenario A1B (a) shows decrease in all stations under scenario A1B (c) and increase in Solan and yalfan under scenario B1(d). Fig 7 (a) - (d) box polt graphs shows Relative changes in50y heavy rainfall days $>=20$. For the future $2045-2065$ for scenario A1B(c) heavy rainfall days decrasing in Yalfan and for scenario B1(d) increasing.

It could be found that three indices in Solan and Yalfan stations for both future periods decreasing under scenario A1B and increasing under scenario B1.Fig 7 (a) -(b) box polt shows graphs of comparing relative changes of three indices and yearly rainfall in50y for the future 2045-2065 under the GCMs model (MPE5, MIHR ) .

Fig 6 (a) shows that relative changes in all indices also yearly rainfall are decreasing for scenario A1B (a) under the GCMs MIHR model .But increasing under scenario B 1(b) at this GCM model. 
(a)

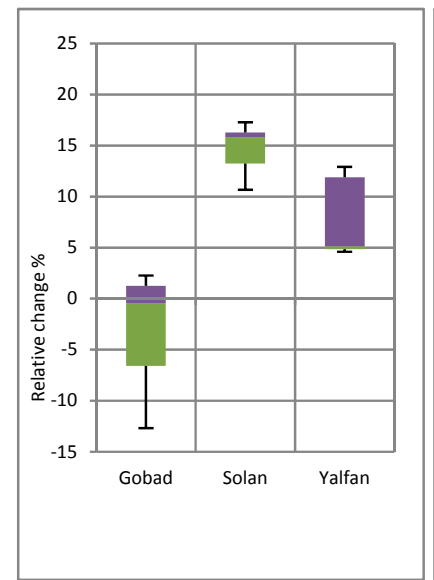

(b)

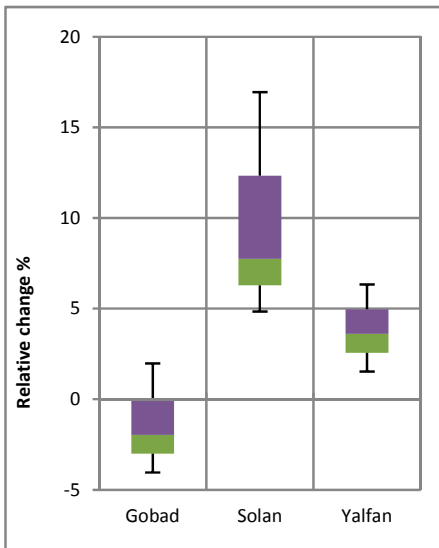

(c)

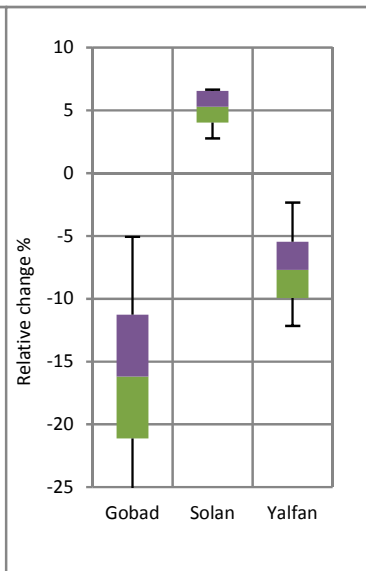

(d)

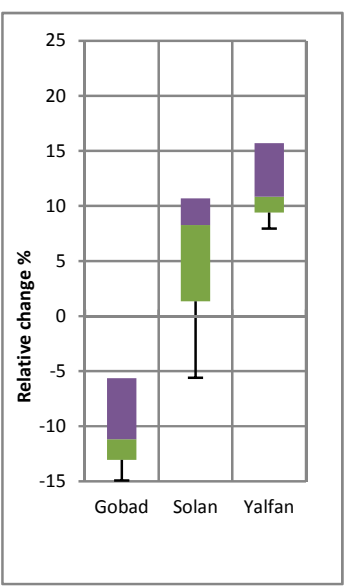

Fig 5 (a) - (d) box polt graphs of Relative changes in50y simple daily intensity index for the future 20202045 for scenario A1B (a), scenario B 1(b) and 2045-2065 for scenario A1B (c) scenario ,B 1(d) under the three GCMs model CMIP3 (MPE5, GIOAM, MIHR ).

(a)

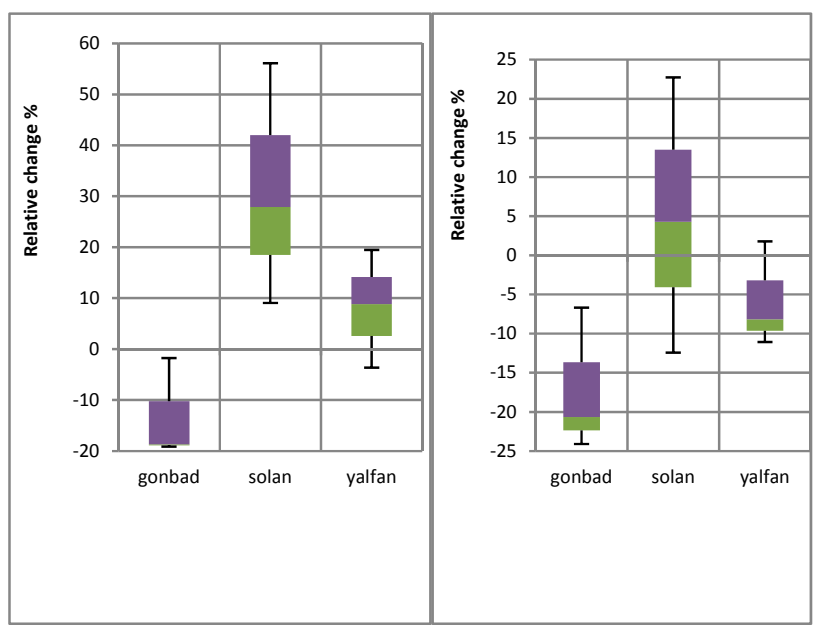

(c)

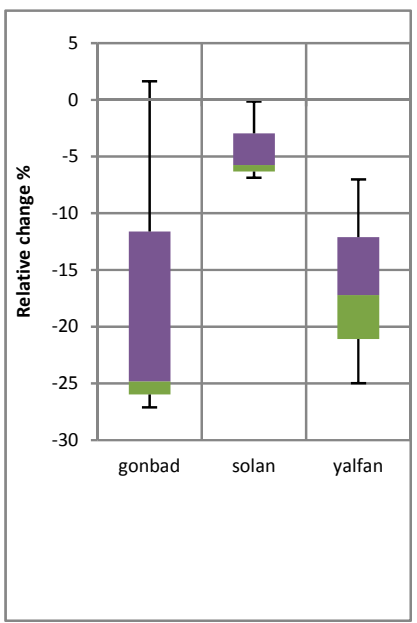

(d)

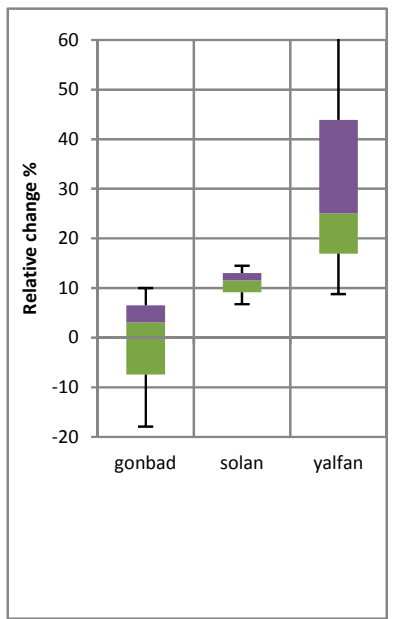

Fig 6 (a) - (d) box polt graphs of Relative changes in50y maximum one-day rainfall for the future 20202045 for scenario A1B (a) ,scenario B 1(b) and 2045-2065 for scenario A1B (c) scenario B 1(d) under the three GCMs model (MPE5, GIOAM, MIHR ) . 
(a)

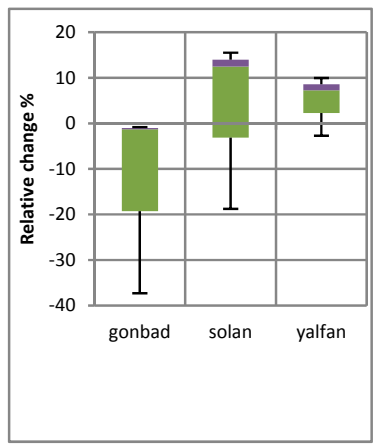

(b)

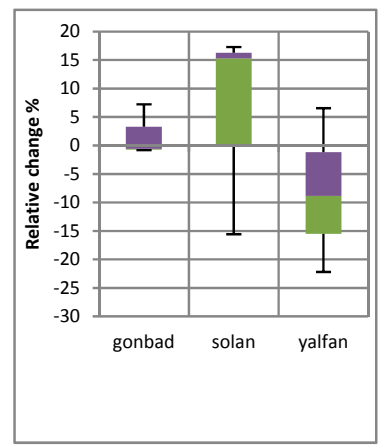

(c)

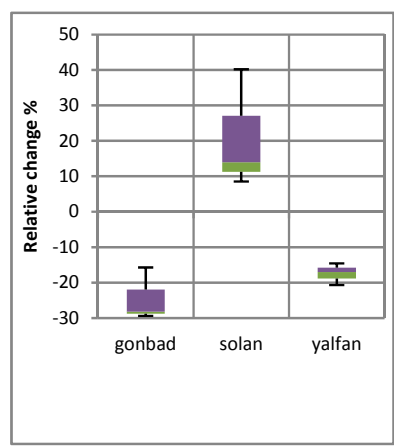

(d)

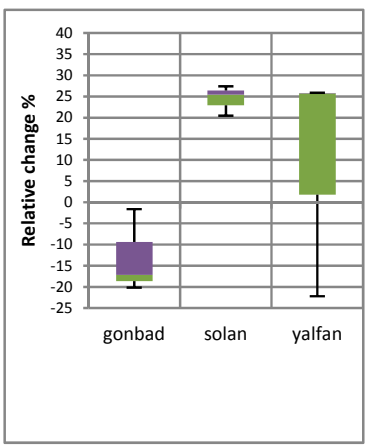

Fig 7 (a) - (d) box polt graphs of Relative changes in50y heavy rainfall days $>=20$ for the future 20202045 for scenario A1B(a) ,scenario B 1(b) and 2045-2065 for scenario A1B (c) scenario,B1(d) under the three GCMs model (MPE5, GIOAM, MIHR ) .

As seen in Fig. 7 (a) - (b) box polt graphs showes Relative changes of three indices and yearly rainfall in $50 y$ decreasing in most of the indices and yearly rainfall for the future period 2045-2065 for scenario A1B under the MPE5 model. But for emmision scenario B1 increasing all of indices and yearly rainfall.

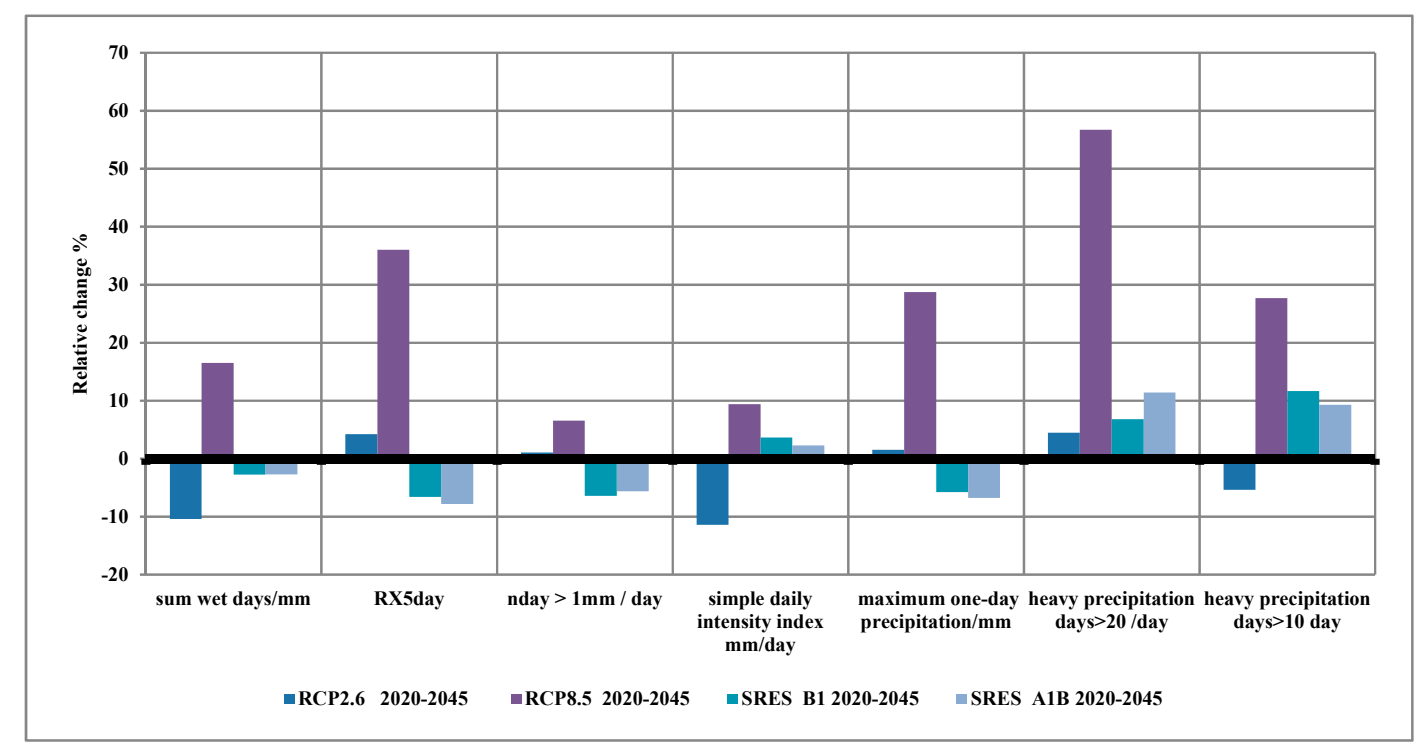

Fig 8. Relative changes rainfall indices for scenario A1B, B1and RCP2.5 and RCP8.5 scenarios for the future 2020-2045 
Rainfall indices of sum wet days, nday $>1 \mathrm{~mm}$ and maximum one-day precipitation are projected to decrease under the senariuos B1,A1B and sum wet days, simple daily intensity and heavy precipitation days $>10$ decrease under the RCP2.6 . While all of Rainfall indices expected to increase in RCP 8.5 scenarios for the future 2020-2045 Fig 8.

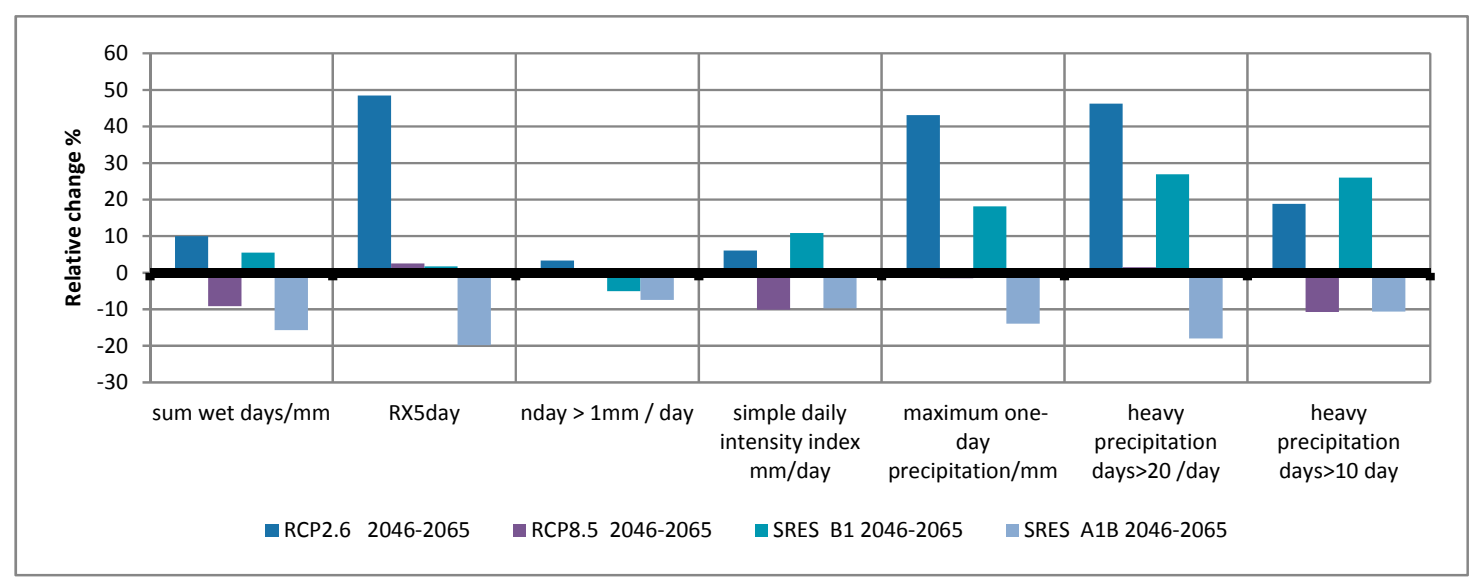

Fig 9. Relative changes rainfall indices for scenario A1B, B1and RCP2.5

and RCP8.5 scenarios for the future 2046-2065

Rainfall indices show relatively considerable changes toward the end of the 21 st century. Analysis of rainfall indices show that except RCP2.6 scenarios and SRES A1B, is predicted to decrease as we progress toward the end of the 21 st century. This indicates significant decreases in the sum of wet days , nday $>1 \mathrm{~mm}$, simple daily intensity and heavy precipitation days (Fig8 a).Also rainfall indices for RCP8.5 scenarios and SRES A1B is predicted to increase toward the end of the 21st century. All of Rainfall indices expected to decrease under the SRES A1B for the future 2046-2065, while predicted to increase in RCP2.6 scenarios Fig 9.

\section{Discussions}

It can be conclude that some uncrtainities exist in CMIP3 and CMIP5 models for the rainfall indices . Fig 5, 6 and 7 show various return periods for emission scenarios CMIP3 models for sum of wet days, heavy rainfall, maximum one-day rainfall and simple daily intensity index . In CMIP3 models and emission scenarios in various return periods predict to large variation for sum of wet days (a), simple daily intensity index (b), maximum one-day rainfall(c) and heavy rainfall days $>=20(d)$ on the (2045-2056) pdriod. 
Analysis of rainfall indices show that except other rainfall indices, heavy rainfall days $>=20 \mathrm{~mm}$ predicted to hieghest under the CMIP3, CMIP5 models and scenarios except RCP2.6 . It can be observe that the return period of simple daily intensity index (b), maximum one-day rainfall(c) under SRES B1 and RCP2.6 scenarios based on CMIP3, CMIP5 models predicted to increase on the (2045-2056) base on the observed period (1983-2010), (Fig9). While return period of sum wet days (a), simple daily intensity index (b) and heavy rainfall days $>=20(\mathrm{~d})$ under the SRES A1B and RCP8.5 scenarios based on CMIP3 , CMIP5 predicted to increase toward the end of the 21 st century.

(a)

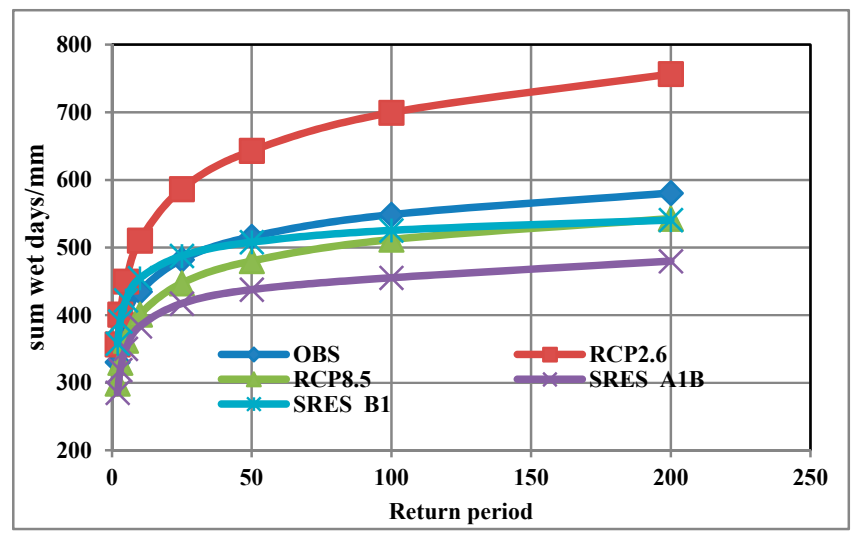

(c)

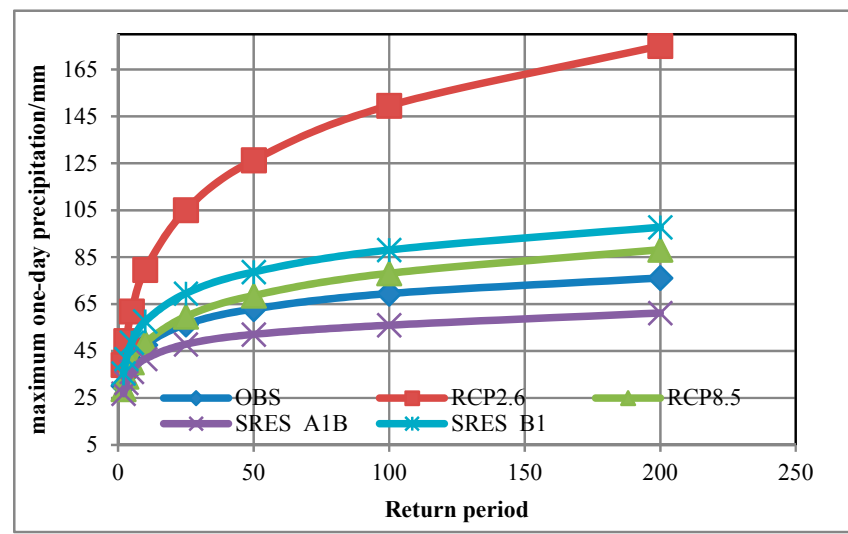

(b)

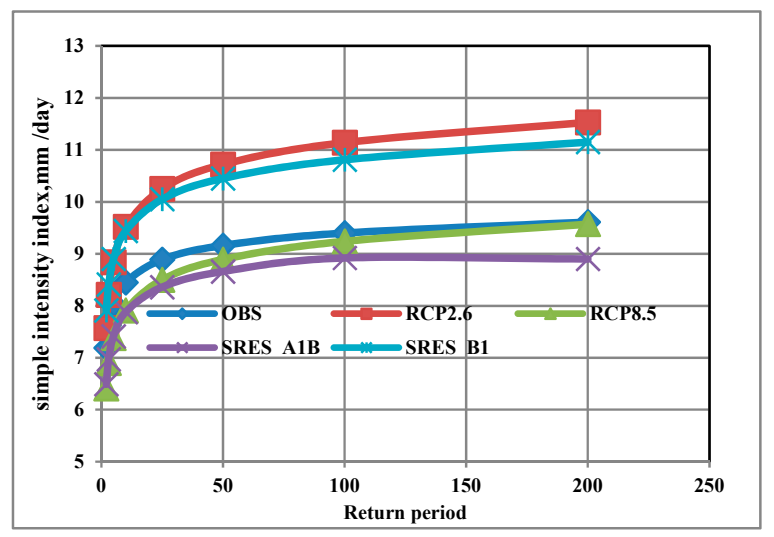

(d)

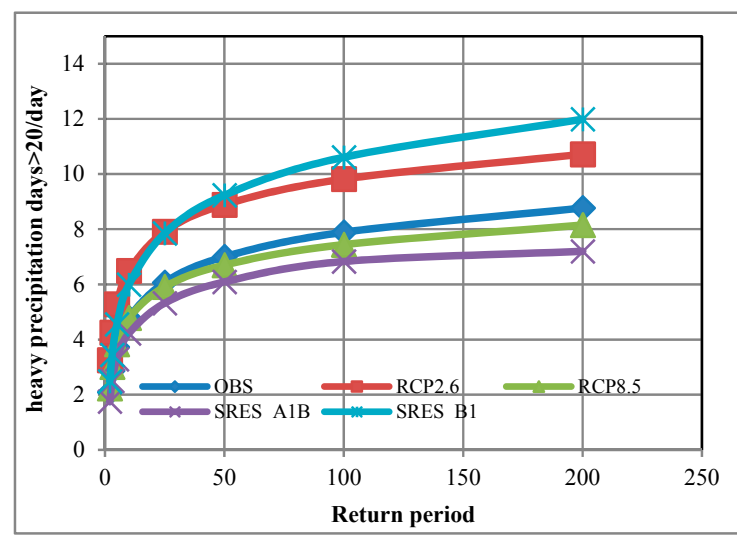

Fig 10. (a) - (d). various return periods under the scenarios A1B, B1 and RCP2.5 and RCP8.5 scenarios for the future 2046-2065 for sum wet days (a), simple daily intensity(b), maximum one-day rainfall(c) and heavy rainfall days $>20(\mathrm{~d})$ index. 
One important assessment of the impact of climate change on rainfall indices is the uncertainty originated from different sources. These sources include future greenhouse gas emission, GCMs, various downscaling methods, impact analysis models and parameter, and so on (Yue-Ping Xu, et al., 2012) .

In this study, CMIP3 , CMIP5 models and emission scenarios have been used. Also to investigate the impact of climate change on extreme rainfall, only one downscaling approach and one probability function (log Pearson Type III probability function), have been used. So different probability cause large uncertainty in extrapolation of extreme rainfalls for large return periods .Based on our current knowledge, this applies to projected changes in rainfall indices over the study area.We focus in this paper on the projected future changes in total precipitation amounts and related indices. Nevertheless it is of utmost importance to also assess the ability of the different models to simulate the observed precipitation characteristics in the region.

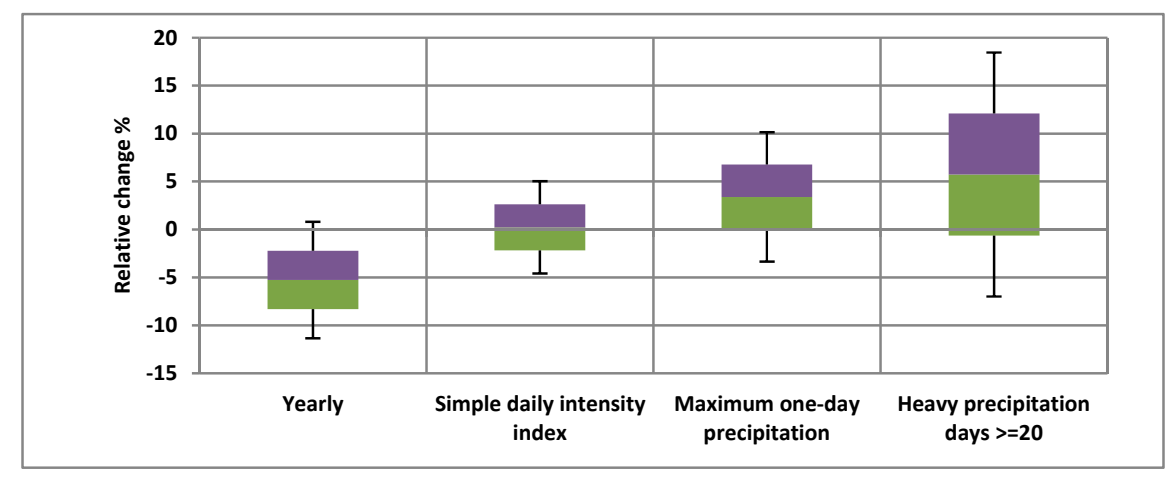

Fig 11. Box polt graphs of Relative changes comparing observed period (1983-2010)with GCMs model under emission scenarios A1B and B1 outputs future period 2045-2065.

Fig 11. Box polt graphs of Relative changes for GCMs model under emission scenarios A1B and B1 observes that, although yearly rainfall deareases in the study area, the indises of heavy rainfall days $>=20$, maximum one-day rainfall and simple daily intensity index increasing for future period 2045-2065 base on the observed period .

\section{5. conclusions}

We use daily precipitation output of a large set of global and downscaled climate change projections available for a historical period and two future periods for several emission scenarios projected changes in 
future precipitation amounts and extremes have been analyzed over kooshkabad watershed, Hamedan Province, west of Iran on the basis of CMIP3 , CMIP5 models ,ensemble and downscaleing climate change projections. This study reveals the noticeable changes due to climate changes in the rainfall indices events over study area. Results showed that the relative changes in monthly rainfall at study area decreasing in rainfall in Jan, Feb, Mars, April , Novamber and Desember.with the lowest uncertainty and increase in rainfall in May, June and Agust with the highest uncertainty.In general one important result of this study is that, an increase of rainfall indices under the most CMIP3 , CMIP5 models and scenarios B1and this inverse for emission scenarios A1B .It could be mentioned that this changes occoure with respect to special and under emission scenarios and GCMs model.This cause to difficulties for water resources managers and planers with such large uncertainty in decision making under climate change. However it is nessesary to investigate rainfall characteristics for future climate conditions. Analysis of return period of heavy rainfall days $>=20$ (a) maximum one-day rainfall (b) simple daily intensity index (c) showed significant decreasing under SRES A1B, RCP8.5 scenarios and increasing under SRES B1, RCP8.5 over study area for CMIP3, CMIP5 models and scenarios. In general results showed that yearly rainfall depth in the study area, decreasing under the three GCMs model for scenarios A1B 11.8\% and scenarios B1 1.44\% for the future period 2045-2065 , but for heavy rainfall days $>=20$ decreasing $8.14 \%$ under the scenarios $\mathrm{A} 1 \mathrm{~B}$ and increasing 13.7\% under the B1 scenarios. Fig 8 showed that although yearly relative changes decreasing for GCMs model under emission scenarios A1B and B1, but slightly increasing observes in heavy rainfall days $>=20$, maximum one-day rainfall and simple daily intensity index in the study area . 


\section{References}

A. Pourtouiserkani and Gh. Rakhshandehroo ,(2014). Investigating climate change impact on extreme rainfall events Case study: Chenar-Rahdar basin, Fars, Iran. Scientia Iranica A (2014) 21(3), 525-533. Albert M.G. Klein Tank, Francis W. Zwiers, and Xuebin Zhang (2009). Analysis of extremes in a changing climate in support of informed decisions for adaptation . Climate Data and Monitoring, World Meteorological Organization .WCDMP-No. 72

Azadeh Ahmadi 1, Moridi, A., Kakaei, E.( 2014). A case study . Journal of Earth System Science Volume 123. The Effects of Climate Change on Extreme Rainfall Events in the Upper Thames River Basin: A Comparison of Downscaling Approaches.

Babaian et al. (2009). studied climate change impact in the Iran in 2010-2039 with downscaling GCM model of ECO-G data. Journal of geography.,Vol 16, pp. 135-152 (2010).

Brown, P. J., R. S. Bradley, and F. T. Keimig.(2010). Changes in extreme climate indices for the northeastern United States. Journal of Climate 23(24): 6555 - 6572.

Chen J, Brissette FP, Leconte R.(2011). Uncertainty of downscaling method in quantifying the impact of climate change on hydrology. Journal of Hydrology 401(3-4): 192-202. DOI: 10.1016/j.jhydrol. 2011.02.020.

Chen, S.-T., P.-S. Yu, and Y.-H. Tang.(2010).Statistical downscaling of daily rainfall using support vector machines and multivariate analysis. Journal of Hydrology 385: 1322.

Eum, H.-I., and S. P. Simonovic. (2012). Assessment on variability of extreme climate events for the Upper Thames basin in Canada. Hydrological Processes 26: 485-499.

Fowler, H. J. and C. G. Kilsby , (2003). Implications of changes in seasonal and annual extreme rainfall. Geophysical Research Letters, Vol. 30, No. 13, 1720, doi: 10.1029/2003GL017327, 2003.

Hashmi, M. Z., A. Y. Shamseldin, and B. W. Melville. (2011). Comparison of SDSM and LARS-WG for simulation and downscaling of extreme rainfall events in a watershed. Stochastic Environmental Research and Risk Assessment 25: 475484. 
Hu, Y., S. Maskey, and S. Uhlenbrook. (2012). Trends in temperature and rainfall extremes in the Yellow River source region, China. Climatic Change 110: 403-429.

IPCC, Intergovernmental Panel on Climate Change, (2007). Fourth Assessment Report,Climate Change. Jeong, D. I., A. St-Hilaire, T. B.M. J. Ouarda, and P. Gachon. 2012. CGCM3 predictors used for daily temperature and rainfall downscaling in Southern Que 'bec, Canada. Theoretical and Applied Climatology 107: 389-406.

Jie Chen , François P. Brissette, (2011). Uncertainty of downscaling method in quantifying the impact of climate change on hydrology Journal of Hydrology 401 (2011) 190-202.

Jones PD, Reid PA. 2001. Assessing future changes in extreme rainfall over Britain using regional climate model integrations. International Journal of Climatology 21: 1337-1356. DOI: 10.1002/ joc.677. Kay, A.L., Davies, H.N., Bell, V.A., Jones, R.G., 2009. Comparison of uncertainty sources for climate change impacts: flood frequency in England. Climatic

Khan MS, Coulibaly P, Dibike Y. (2006). Uncertainty analysis of statistical downscaling methods. Journal of Hydrology 319: 357-382. DOI: 10.1002/hyp.6084.

Leanna M. M. King, Sarah Irwin , Rubaiya arwar . (2014).Assessment of climate change impacts on rainfall using large scale climate variables and downscaling. Canadian Water Resources Journal / Revue canadienne des ressources hydriques, 37:3, 253-274, DOI: 10.4296/

Mailhot A, Duchesne S, Caya D, Talbot G. (2007). Assessment of future change in intensity-durationfrequency (IDF) curves for Southern Quebec using the Canadian Regional Climate Model (CRCM). Journal of Hydrology 347:197-210. OI:10.1016.

Massahbavani, A. and Sadatashofteh, P. ( 2010). Impact of climate change on maximum discharges: Case study: Aidoghmoosh watershed, East Azerbaijan, Iran" Iranian Journal of Agricultural Science and Technology and Natural Resources, 53, pp. 25-39 (2010).

May W. (2004). Simulation of the variability and extremes of daily rainfall during the Indian summer monsoon for present and future times in a global time-slice experiment. Climate Dynamics 22: 183-204. DOI:10.1007/s00382-003-0373-x. 
Minville M. Brissette F, Leconte R. (2008). Uncertainty of the impact of climate change on thehydrology of a Nordic watershed. Journal of Hydrology 358:70-83. DOI: 10.1016

Schoof, J. T. (2012). Scale issues in the development of future rainfall scenarios. Journal of Contemporary Water Research and Education 147:8-16.

Semenov MA, Brooks RJ, Barrow EM, Richardson CW. (1998). Comparison of the WGEN and LARSWG stochastic weather generators in diverseclimates. Climate Research10:95-107. DOI:10.3354/cr010095.

Semenov MA, Stratonovitch P.(2010). Use of multi-model ensembles from global climate models for assessment of climate change impacts. Climate Research 40(1): 1-14. DOI: 10.3354/cr00836.

Dong, S. Y., Y. Xu, B. T. Zhou, et al. ( 2014): Projected risk of extreme heat in China based on CMIP5 models, Adv. Climate Change Res. (in Chinese), 10(5), 365-369.

Semenov MA.(2008). Simulation of extreme weather events by a stochastic weather generator. Climate Research 35:203-212.DOI: 10.3354/cr00731. Semenov MA, Brooks RJ. 1999. Spatial interpolation of the LARS-WG stochastic weather generator in Great Britain. Climate Research 11: 137-148. DOI: $10.3354 / \mathrm{cr} 011137$.

Solaiman, T., L. King, and S. P. Simonovic. (2010).Extreme rainfall vulnerability in the Upper Thames River basin: Uncertainty in climate model projections. International Journal of Climatology 31: 23502364. doi: $10.1002 /$ joc. 2244 .

Tomozeiu, R., C. Cacciamani, V. Pavan, A.Morgillo,and A. Busuioc. ( 2007). Climate change scenarios for surface temperature in Emilia-Romagna (Italy) obtained using statistical downscaling models. Theoretical and Applied Climatology 90: 2547.

Von Stoch, H., Zorita, E., Cubasch, U. (1993). Downscaling of global climate change estimates to regional scales: an application to Iberian rainfall in wintertime. Journal of Climate 6, 1161-1171.

Wetterhall, F., S. Halldin, and C.-Y. Xu. ( 2007). Seasonality properties of four statistical-downscaling methods in central Sweden.Theoretical and Applied Climatology 87: 123137. 
Wilks DS. (2010). Use of stochastic weather generators for rainfall downscaling. Wiley Interdisciplinary Reviews Climate Change 1(6): 898-907. DOI: 10.1002/wcc.85.

Wilks, D.S., (1999. Multisite downscaling of daily rainfall with a stochastic weather generator. Climate Research 11, 125-136.

Wilks,D.S.(2010.Use of stochastic weather generator for rainfall downscaling.Climate Change.1,898-907.

Xu C, Shen X, Xu Y. ( 2007). An analysis of climate change in East Asia by using the IPCC AR4 simulations. Advances in Climate Change Research 3(5): 287-292 (in Chinese).

Chen, H. P. ( 2013: Projected change in extreme rainfall events in China by the end of the 21st century using CMIP5 models, Chin.Sci. Bull., 58, 1462-1472.

Chen, X. C., Y. Xu, C. H. Xu, et al. ( 2014): Assessment of precipitation simulations in China by CMIP5 multi-models, Adv. Climate Change Res. (in Chinese), 10(3), 217-225.

Andreas Haensler \& Fahad Saeed \& Daniela Jacob (2013).Assessing the robustness of projected precipitation changes over central Africa on the basis of a multitude of global and regional climate projections. Climatic Change, DOI 10.1007/s10584-013-0863-8.

Seree Supharatid (2015) studied assessment of CMIP3-CMIP5 climate models precipitation projection and implication of flood vulnerability of Bangkok. American Journal of Climate Change, 2015,4,140-162.

Xu Ying, Wu Jie, Shi Ying, Zhou Bo-Tao, Li Rou-Ke \& Wu Jia (2015) Change in Extreme Climate Events over China Based on CMIP5, Atmospheric and Oceanic Science Letters,8:4, 185-192

Fahad Saeed, Andreas Haensler, Torsten Weber, Stefan Hagemann and Daniela Jacob (2013). Representation of Extreme Precipitation Events Leading to Opposite Climate Change Signals over the Congo Basin. Atmosphere 2013, 4, 254-271; doi:10.3390/atmos4030254.

Botao Zhou, Qiuzi Han Wen, Ying Xu and Lianchun Song, Xuebin Zhang, (2014). Projected Changes in Temperature and Precipitation Extremes in China by the CMIP5 Multimodel Ensembles. American Meteorological Society .27, 6591-6611. 